(representing Belgium, France, Germany, Italy, Luxembourg and the Netherlands), Norway, Sweden, Switzerland and the United Kingdom. It provides for a joint programme, budget and staff for research and development work with the reactor for a period of three years. Through agreements with the Institutt for Atomenergi, the United States and Finland are also associated with the reactor project. At present, a professional staff of thirty, recruited from the participating countries, is attached to the project. During the next six months the reactor will be operated at low power-levels to enable fundamental reactor physics experiments to be performed. After this period the power level will be increased gradually up to the design power of $10 \mathrm{MW}$. thermal energy.

The reactor plant will be officially opened by H.M. King Olav on October 10.

The Halden Reactor Project is one of several joint undertakings sponsored by the European Nuclear Energy Agency of the Organization for European Economic Co-operation; others are the 'Eurochomie' company for the chemical processing of irradiated fuels (established by an international convention signed in December 1957) and the Dragon hightemperature gas-cooled reactor project, work on which began last April.

\section{THE DANISH ATOMIC}

T THE report on the activities of the Danish Atomie Energy Commission* for the period April 1, 1957, to March 31, 1958, deals mainly with the erection of the Risø Research Establishment and the three reactors $D R 1, D R 2$ and $D R 3$, and the work of the six departments of the Establishment. The membership of the Commission remained unchanged during the period under review, and Prof. Niels Bohr continued to act as chairman. The total cost of the Establishment was originally estimated at about 100 million kroner. The expenditure so far, including that estimated for 1958-59, is about 90 million kroner, of which about 60 million kroner is for expenditure on buildings and the remainder for the three reactors and the requisite technical and scientific equipment. On March 26, 1958, the Finance Committee authorized an additional expenditure of up to $2 \cdot 5$ million kroner on a linear accelerator to be used for experiments on the preservation of food and for other irradiation experiments.

On August 15, 1957, the first of the three reactors began to operate, and by September the chemical, reactor engineering, electronics and physics laboratories together with the administration building were completed and in use. Then followed the health physics department, the library and the canteen, and early in 1958 the agricultural department, the lecture hall and the buildings to house the DR2

* Report on the Activities of the Danish Atomic Finergy Commission for the period from 1 April 1957 to 31 March 1958. Pp. 62. (Copenhagen: Danish Atomic Fnergy Commission, 1958.)

\section{ENERGY COMMISSION}

reactor group were completed, leaving only the buildings for the $D R 3$ reactor to be erected. A detailed map attached to the report shows the complete layout of the Establishment.

In the physics department one group has been working on the construction of a laboratory for investigations of beta- and gamma-ray activities; another group with neutron spectroscopy; and a third group with solid state physics, particularly the study of the effects of radiation damage to metals and graphite. A study has also been made of the literature on deuterium fusion and of the theoretical aspects of the utilization of the energy from deuterium fusion. The electronics department has undertaken active research on scintillation counters and on the development of a reactor simulator. Two study groups were formed in the reactor engineering department. The first was engaged in drafting a project for a heavy-water-moderated power reactor with an organic cooling medium, and the sccond for a high-temperature gas-cooled reactor.

A section of the report is devoted to the International Atomic Energy Ageney, and to regional co-operation in Europe, including the Organization for European Economic Co-operation and Euratom. The report also gives details of geological surveys in Greenland; relations between the Commission and commerce and industry; educational activities which included experimental reactor courses with $D R 1$ and lecture courses at the Technical Universitr of Denmark; and general information services.

\title{
ATOMIC POWER CONSTRUCTIONS, LTD.
}

$\mathrm{A}^{\mathrm{T}}$ TOMIC POWER CONSTRUCTIONS, LTD., 28 Theobalds Road, London, W.C.1, which was formed in December 1956, is carrying out extensive research and development in connexion with the national nuclear power effort. The research programme is concentrated at the company's laboratories at Heston, Middlesex, and a booklet* recently prepared gives a survey of the problems being tackled. In the Calder Hall type of reactor the uranium is arranged in a pattern of vertical rods embedded in a large cylindrical 'core' of graphite. The heat generated in the rods is carried away by blowing carbon dioxide gas past them, and in order to economize in pumping power the reactor designer puts the

* Research and Development at the Heston Laboratories of Atomic Power Constructions, Limited. Pp. 10. (London: Atomic Pore Constructions, Ltd., 1959.) whole of the carbon dioxide gas circuit under a pressure of some 20 atmospheres. Consequently, the core and uranium must be enclosed in a pressure vessel.

Most stringent precautions must be taken against failure of the pressure circuit in which the carbon dioxide circulates, and a major part of the work undertaken by Atomic Power Constructions, Ltd., is concerned with proving the materials and fabrication techniques which are used in the construction of the pressure vessel. An important problem is creep of the steel to be used for the pressure vessel and for the heat exchangers, and in order to aequire the necessary information sufficiently quickly an airconditioned creep laboratory containing a battery of seventy creep machines has been set up. The strain ageing of steels at elevated temperatures; weld- 
ability and welding techniques for use with selected steels ; and the chemical compatibility of the various materials used in the reactor with the carbon dioxide coolant gas, are some of the other problems being investigated by the Metallurgical Division. A considerable expansion in facilities is planned during 1959 , and additional long-term researches relating to uranium, magnesium and the weldability of steel will be started. The design of the best heat transfer surface for the fuel elements is at present largely empirical and at the Heston Research Laboratories two experimental rigs are provided for experimental tests. In both, the fuel element can is placed in a working section and the heat developed in the uranium simulated by an electric heater. Facilities for basic studies in heat transfer and in other design problems have also been set up, and these facilities comprise a flow visualization rig and associated equipment in which water replaces the pressurized carbon dioxide as the working fluid.

Crompton Parkinson, Ltd., the Fairey Aviation Co., Ltd., International Combustion (Holdings), Ltd., Richardsons Westgarth and Co., Ltd., and Nuclear Civil Constructors (Trollope and Colls, Holland and Hannen, and Cubitts) form the five member companies of Atomic Power Constructions, Ltd.

\section{COFFEE RESEARCH IN THE BELGIAN CONGO}

\begin{abstract}
$\mathrm{T}$ WO investigations of a fundamental character on the genus Coffea have recently been published by the Institut National pour l'Etude Agronomique du Congo Belge, (i) Recherches sur l'Autostérilité du Caféier Robusta (Coffea canephora Pierre) by M. Devreux, G. Vallaeys, P. Pochet and A. Gilles (No. 78. 1959. Pp. $44+8$ plates. 40 franes); (ii) Recherches sur les Affinités Chromosomiques dans le Genre Coffea by J. Bouharmont (No. 77. Pp. $94+2$ plates. 70 francs). The self-sterility of Robusta coffee has been known in a somewhat confused way for many years, but no convineing demonstration of this phenomenon has previously been presented. This information is important in preparing a rational programme of selection. The investigators of the work indicated above have now shown, under strictly experimental conditions, that this variety is quite self-sterile. As a result of many controlled self-pollination experiments, using 19 clones and based on a very large number of flowers, for example, more than 15,000 in one instance, an extremely small number of fruits has been obtained, the highest percentage not exceeding 0.24. By contrast, when the flowers of the same clones were subjected to cross-pollination, a number of ripe fruits, 30-40 per cent, was obtained. The self-sterility is not attributed
\end{abstract}

\section{BOTANY IN}

A $\mathrm{N}$ agreeable and very well-deserved tribute has been paid to Prof. J. R. Matthews, regius professor of botany in the University of Aberdeen, by his friends, past and present colleagues and former students, on the occasion of his seventieth birthday. During his twenty-five years as regius professor he has greatly increased the stature of his Department, has helped the cause of botanical science by his work on the councils of various societies and has made many valuable contributions to botany, especially in the field of research relating to the origin and distribution of the British flora. The presentation volume under consideration has been printed for the Botanical Society of Edinburgh and appears as a special number of the T'ransactions (38; March 1959. 15s.). There is a foreword by $\mathrm{H}$. R. Fletcher, and, as might perhaps be expected, a number of the articles relate to the ecology of Scottish plants. But there are also some contributions dealing with other aspects of botanical science, for example, "Some Fundamental Considerations on the New Morphology", by H.J.Lam; "Peristome Teeth and Spore Discharge in Mosses", by to defects in floral structure or in micro- or macrosporogenesis but to anomalies in the formation and growth of the pollen-tubes. In no case were these able to traverse the style. While a genetical explanation in terms of incompatibility may be advanced, validation has still to be obtained.

Observations on the chromosome numbers of thirteen species of Coffea, including all the well-known species such as $C$. arabica, $C$. liberica, $C$. stenophylla, etc., have shown that all those examined are diploid with 22 chromosomes, except $C$. arabica which has 44. Certain hybrids are diploid and others tetraploid. The nuclear behaviour at mitosis is apparently identical in all the species. Measurements of chromosome lengths show that these are all much alike. It is considered that these comparisons by measurement confirm the close systematic relation of certain species, but it does not enable a general classification of the genus to be established. An average idiogramme of the African Coffea has been prepared. The author concludes that the genus is a very homogeneous one, and that the species investigated are closely related from the cytological point of view. Lastly, this investigation has vielded no evidence of difficulties in obtaining interspecific hybrids.

\section{SCOTLAND}

C. T. Ingold ; a biographical essay on "The Rev. John Walker (1731-1804) - a Notable Scottish Naturalist", by G. Taylor, of the Royal Botanic Gardens, Kew ; and J. Grant Roger has contributed a useful article on the "Conservation of the Scottish Flora".

Further evidence of the work of this distinguished and active botanical society has also been published (Trans., 37, Part 4; 1959). This is devoted entirely to various aspects of Scottish botany. Thus there are floristic studies of a number of different regions, sometimes combined with geological observations. D. Ratcliffe has contributed an article on the "Habitat of Koenigia islandica" ; and D. G. Downie on "Rhizoctonia solani and Orchid Seed". There is a special cryptogamic section by D. M. Henderson and an alpine section by D. Grant Roger. There is also a useful general article dealing with botanical research in Scotland. This gives a brief account of the activities of the main research institutes, including those devoted to marine biology and nature conservancy, but it is not concerned with university departments of botany. 